\title{
Ontology-based Course Teacher Assignment within Universities
}

\author{
Ghadeer Ashour $^{1}$, Ahmad Al-Dubai ${ }^{2}$, Imed Romdhani ${ }^{3}$ \\ Sch. of Computing \\ Edinburgh Napier University \\ Edinburgh, UK
}

\begin{abstract}
Educational institutions suffer from the enormous amount of data that keeps growing continuously. These data are usually scattered and unorganised, and it comes from different resources with different formats. Besides, modernization vision within these institutions aims to reduce human action and replace it with automatic devices interactions. To have the full benefit from these data and use it within the modern systems, they have to be readable and understandable by machines. Those data and knowledge with semantic descriptions make an easy way to monitor and manage decision processes within universities to solve many educational challenges. In this study, an educational ontology is developed to model the semantic courses and academic profiles in universities and use it to solve the challenge of assigning the most appropriate academic teacher to teach a specific course.
\end{abstract}

Keywords-Semantic; university ontology; academic profile; syllabus; course-teacher assignment

\section{INTRODUCTION}

Many Organizations in recent years have benefited from the role and impact of the Semantic Web to support decision making and planning processes. In education, Universities have tried to follow the modernization and compete with each other. This step caused many challenges in the domain of education. One way to win the competition is to replace the old traditional systems with modern technologies.

Semantic technology has been used to present data within many universities for the purpose of solving the challenges in the educational domain. As an instance, it has been used to optimize evaluation processes and decision making. Although the noticed use of semantic in the educational field, this technology still has not covered several possible areas.

Higher Education Institutes (HEI), especially Universities, are producing Knowledge continuously; thus, the created academic and administrative materials must be stored in record. Because of the enormous amount of information received by higher education institutions and the distinctive features of heterogeneous information systems that can vary within the same organization, the use of knowledge representation technologies makes systemic information important [1].

The main objective of this study is to use basic concepts and relationships in ontology to exploit the enormous amount of unstructured data in universities by building a university ontology. Besides, the proposed ontology is used to facilitate the process of assigning the courses to teachers within universities, as the complications related to this process are considered one of the most important challenges that appear frequently at the beginning of each academic year.

The study will be applied to King Abdulaziz University (KAU) in Saudi Arabia and concentrated on the Faculty of Computer and Information Technologies (FCIT). Additionally, the proposed framework would be considered to be smart enough to be compatible with domain data and to conduct resource matching and analysis.

This paper is organized as follows: Section 2 mentions the challenges in higher education. Then, recent works for university ontologies are discussed in Section 3. After that, the steps of developing the ontology are described in Section 4 including the evaluation. The main results and the future works are discussed in Section 5 followed by the conclusion in Section 6.

\section{RELATED WORKS}

\section{A. Challenges in Higher Education}

Higher Education is considered as the core of building the future in the whole wide world since it produces the employees for all institutions in different specializations. So, it needs to be provided with all the elements that guarantee efficient performance. Higher education involves various practices not only in teaching and learning but also in researches, employment, and decision making.

During the last decade, a modern vision of education has spread over the educational institutions which force most of the universities to move to a new education [2]. This modernization led to several challenges that require replacing the traditional information systems with the new techniques to solve them. Therefore, many of these challenges have been addressed by several researchers. Besides, different improved systems have been produced to solve these problems.

The most common challenges in higher education were reviewed in [3] and [4]. The author in [4] represented 20 challenges based on the recent appeared changes in higher education, students, and learning style over the last decade. The most significant challenges the author summarized are as follows:

- Quality of learning and teaching.

- Quality of research. 


\section{- Accreditation.}

- Compete and collaborating globally in research and talent.

- Student retention.

- Assessment.

- A new generation of staff.

- Group formation for learning and teaching.

- Higher education governance and management

Solving these challenges starts with the correct use of the available information across institutional repositories, as the author has mentioned, and specifies what information can be shared [5].

The study in [3] has examined the use of big data and analytics to address higher education challenges. The paper classified the current trends affecting higher education as economic, technological, educational, and social changes. These changes cause challenges related to academic programming, research, teaching, and learning. The researcher argued that a huge amount of data in a different format from different sources is generated all the time which leads to scattered and difficult to retrieve data. Using big data and analytics methodologies improve the use of these data and help in making better decisions within educational institutions.

Several studies have demonstrated many systems that aim to solve problems in higher education. Some of these studies have used single sources and others have used citation and external open data. The semantic technology was one of the leading solutions that were applied in different aspects of education.

This study focuses on the challenge of assigning the most proper academic teacher to teach a new course. It is one of the popular challenges universities are facing continuously. It depends on matching course contents with resource expertise. Every time, traditional processes are used by the head of departments to decide the best matching. Usually, the first step is reading the contents of the course, topics to be taught, practical material, etc. Then, the CVs of faculty members are checked by focusing on their research interests, scientific publications, teaching experience, etc. The matching results are ordered in different ranks/marks for different faculty members. After that the best possible one is assigned. Performing this job manually on a huge amount of data is time-consuming and could produce inaccurate results. Also, the increase in the number of Ph.D. holders' staff within universities and the amalgamation in their interested research areas makes the decision of the courses' distribution process more complicated.

On the other hand, the proposed ontology can manage the need for collaboration between the university's departments and faculties. Every teaching term, for different reasons, some faculties have a shortage in the number of their staff while the number is excess in other faculties. By matching the topic of any course with any academic teacher profile that has the same specialty within the university the problem could be solved.

\section{B. Educational Ontologies}

In many cases, the data at hand is represented in semistructured forms such as the tabular representation that is found in documents, spreadsheets, and on the web database. This kind of data, not similar to relational databases, follows a simple structure with no schema represented or specified. This means that humans can understand these data easily while machines cannot deal or process them since it is not in a formal representation and not backed by a specific schema [6]. Through ontology, data are available in digital form, which can be used by people as well as machines for sharing and developing knowledge-based systems [7].

Wading into using Semantic Web technologies in education would be essential because of the nature of the educational data that can create useful opportunities for educational institutions to improve their performance. So, educational ontologies can be used as a solution in many aspects of education since it can overcome the overloading information problem. During the past decade, the technology of the semantic web has been used by a significant number of studies within the educational domain which play a core role in solving most complicated challenges in different fields, such as information integration and sharing, web service annotation and discovery, and knowledge representation and reasoning [8].

Although the subject area of ontological technology in education is comparatively new, efforts have revealed that ontology-based tools and applications offer significant educational assistance and become one of the smartest research fields in education technology.

The study in [9] shows the development of a semiautomated educational instructor to help students in choosing learning paths (consisting of a collection of courses that outline the specific curricula) to complete a certain professional profile. They developed the Academic Tutor bearing in mind the situation of an Electrical Engineering Curriculum described by ontologies, a Semantic Web system that offers a logical and formal definition that people and machines can understand.

An Ontology-based Personalized Course Recommendation (OPCR) semantic recommendation model is suggested in [10]. The purpose of this system is to support students to pick the best curriculum from the vast number of courses accessible on the internet that suit their individual wishes. Therefore, the system uses an educational ontology method to seek similarity in student and course profiles considering future work for every student. Based on the outcomes and user feedback, OPCR has increased the reliability of recommendations relative to the matching approaches used in conventional recommendation systems for keywords.

Moreover, the Open University Is investigated in [11]. It has used semantic technology to describe information about published materials, teacher research work, titles, courses, and audio-visual educational resources. These data have been reusable and accessible to others by providing a SPARQL 
endpoint. Since some universities have moved from traditional learning to digital learning by providing Open Educational Resources (OERs), the linked data vision demonstrated by software interface enables a new generation of OERs and Open Course Ware (OCW) that can be semantically described and connected with other data and discoverable sources. These resources include tools and materials needed to support education to be freely accessed, reused, modified, adapted, and shared by anyone. The researchers introduced a vocabulary using W3C's RDF technology called Linked Open Course Ware Data (LOCWD). It links OERs, open licenses, OCW repositories, and other academic information using the web. The main idea of these vocabularies is to connect the described OCW domain with Datasets in the LOD cloud.

An ontological approach for semantic modelling of curriculum and syllabus in higher education is proposed in [12]. This study aims to introduce a learning ontology model that improves the usability of curriculum, syllabus, learning subject, and learning materials. Also, it develops services based on the proposed approach such as aligning curriculum, classifying syllabus, retrieve concepts of syllabuses and curriculum semantically, and recommending adaptive learning paths. This curriculum ontology can be used to combine numerous department curricula of the same discipline or to allow several subjects to converge. Also, a classification scheme for the syllabus and learning ontologies were provided by this ontology.

Another educational ontology is proposed in [13]. It is semantically modelling the main concepts in curriculum and syllabus in higher education considering the national and international accreditation rules.

The developed ontology in the next section will use the advantages of semantic and describe the needed educational data to solve the assigned educational challenge.

\section{Ontology DeVElopment Method}

Many methods and tools have been emerged to develop ontology based on the purpose of the educational ontology. The design of our ontology is following the guideline mentioned in [14] and [15]. It includes the steps in Fig. 1 below:

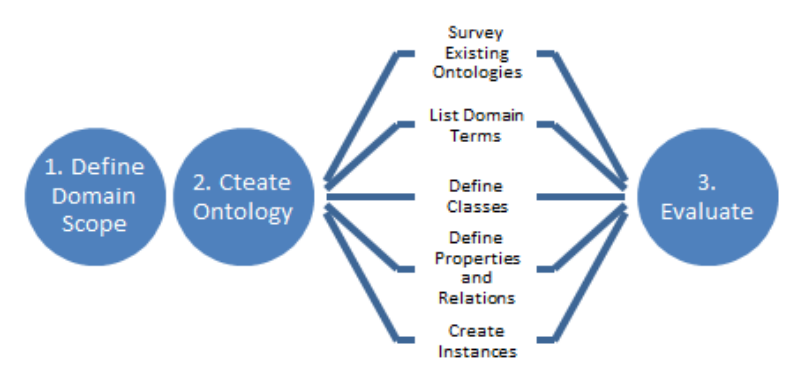

Fig. 1. Ontology Development Methodology.

\section{A. Define the Domain}

1) Selected scenario: This proposed ontology aims to treat the problem of assigning academic teachers with courses using semantic technology. So, course description and details, and the faculty profile are transferred from unstructured textual data to RDF format. Then, we can perform the reasoning on the resulting RDF data by applying SPARQL queries and find the best possible resource for a course in minimum time with the best suitable match.

As an essential process, before starting developing the ontology, we need to review the official documents that represent academic staff profiles and courses' descriptions to elicit concepts and identify the main relationships.

This study will be applied to the KAU data as a proof of concept and, particularly, the Faculty of Computer and Information Technologies (FCIT) will be the case study. The ontology has to describe staff committees and courses of KAU.

a) KAU Data Design: In the Kingdom of Saudi Arabia (KSA), all the institutes of higher education, including KAU, must be accredited by the National Commission for Academic Accreditation \& Assessment (NCAAA) as requested by the Ministry of Education (MoE). Therefore, they are considering the NCAAA rules when they prepare their data for accreditation. The NCAAA accreditation and quality assurance criteria are designed in compliance with international standards and apply to Saudi Arabia's requirments [16].

b) FCIT General Information: FCIT consist of three main departments that are:

- Department of Computer Science

- Department of Information System

- Department of Information Technology

Each department offers different programs. The focus of this paper is on the bachelor courses only. The number of courses offered by the faculty for bachelor degrees is shown in Table I. Also, the table mentions the number of academic members of FCIT. Each department within FCIT has a number of academic teachers who are holding different degrees as follow:

- Ph.D. holders

○ Professor

- Associated Professor

- Assistant Professor

- Non-Ph.D. holders

- Lecturer

- Teaching Assistant 
TABLE I. FCIT COURSES AND ACADEMIC STAFF DETAILS

\begin{tabular}{|l|l|l|l|}
\hline Department & $\begin{array}{l}\text { No of academic } \\
\text { teachers }\end{array}$ & $\begin{array}{l}\text { No of Ph.D. } \\
\text { holders only }\end{array}$ & $\begin{array}{l}\text { No of bachelor } \\
\text { courses }\end{array}$ \\
\hline Computer Science & 109 & 51 & 44 \\
\hline $\begin{array}{l}\text { Information } \\
\text { Science }\end{array}$ & 99 & 45 & 41 \\
\hline $\begin{array}{l}\text { Information } \\
\text { Technology }\end{array}$ & 106 & 53 & 34 \\
\hline
\end{tabular}

c) Syllabus: It is an organized document that is prepared by the teacher to represent the main information about a course. It can be used as a reference and guidance by both teachers and students. Currently, there is no unique format for representing the syllabus in universities around the world. Syllabus is usually represented according to NCAAA format using the following components:

- Course code

- Course Credit

- Prerequisite Course

- Course Classification

- Class Schedule

- Textbook

- Grade Distribution

- Last Articulated

- Relationship to Student Outcomes

- Course Learning Outcomes (CLO)

- Coordinator(s)

- Topic Coverage Durations

d) Academic staff profile : It is a document that contains all the official information about an academic staff. It focuses usually on background in educational administration, program management, academic skills, degree, expertise, publications, and interesting research area. There is no stable form of the academic staff CVs. Each educational institution has a different template to organize its staffs' information. The following components are used to describe the academic staff profiles in NCAAA format:

- Staff name

- Staff rank

- Department

- Department Contact Information

- Highest Degree

- Scientific and Professional Affiliation

- Academic and Professional Experiences

- Certifications and Trainings

- Research Areas of Interest

\section{- Recent Publications ( Last 20 Years )}

2) Competency Questions: Competency questions (CQs) is a technique that is used to test the efficiency of an ontology. It consists of several questions that should be answered by the information provided by the ontology. Basically, these questions are sketched to define the scope of ontologies and specify the requirements and the needs the ontology will fulfill. On the other hand, they can be used later to evaluate the ontology. The most important CQs are:

- What are the courses provided by a given department?

- What is/are the prerequisite course(s) of a given course?

- Who is/are the coordinator(s) for a given course?

- What are the topics of a given course?

- What are the learning outcomes of a given course?

- Which course(s) cover a given knowledge area?

- Who can teach which course?

- Which academic teacher is the best to teach a specific course?

- What are the interested search areas for a given academic teacher?

- Which course is best to be taught by a specific academic teacher?

Table II shows some examples of CQs with their expected answers.

\section{B. Building the Ontology}

After reviewing the textual official documents, they will be transferred into the RDF format. Then SPARQL queries will be applied to extract suitable answers to our research questions.

To develop our ontology, it is important to choose a suitable ontology editor. Protégé editor is chosen since it is considered as one of the best common ontology creation and information demonstration tools built over nearly 20 years [17].

TABLE II. EXAMPLES OF COMPETENCY QUESTIONS

\begin{tabular}{|l|l|}
\hline CQs Example & Expected Answer \\
\hline - Who can teach which course? & $\begin{array}{l}\text { A list of all the academic teachers that } \\
\text { possibly can teach each course in the } \\
\text { department depending on their } \\
\text { interested research areas that match the } \\
\text { topics of each course }\end{array}$ \\
\hline $\begin{array}{l}\text { Which academic teacher is } \\
\text { the best to teach a particular } \\
\text { course? }\end{array}$ & $\begin{array}{l}\text { A list of all the academic teachers that } \\
\text { possibly can teach a course depending } \\
\text { on their interested research areas that } \\
\text { match the topics of the particular } \\
\text { course }\end{array}$ \\
\hline $\begin{array}{l}\text { Which course is best to be } \\
\text { academic teacher? }\end{array}$ & $\begin{array}{l}\text { A list of all the possible courses that } \\
\text { can be taught by an academic teacher } \\
\text { according to the topics }\end{array}$ \\
\hline
\end{tabular}


1) Reusing existing ontologies: Most of the development methodologies recommend considering reusing existing ontologies before starting a new one. This step can help with two faces. First, if a developer finds an ontology that matches his requirements, he can save time and reuses it. Second, he can extend his experience in the development process when it is impossible to find a matched one.

To decide the ability to reuse any of the current ontologies, several related works reviewed to evaluate whether they can model our information. The possibility of reusing the selected ontologies was examined based on the following criteria:

- The purpose and the core concepts of the ontology

- The structure of the ontology (the vocabularies and the relations should meet our needs)

- The language used to create it (the ontology should be available in RDF format)

- The tools used to create it

- The license (the selected ontology should be legally allowed to be reused by other researchers or institutions)

- The availability (is it available online or not)

The literature review below focuses on the current studies describing syllabus and curriculum semantically since they are considered as a skeleton to any educational ontology.

Academic Institution Internal Structure Ontology (AIISO) is a university ontology that emphases on the university domain's systemic perspective. It describes the roles that people within an academic institution play by connecting with Participation ontology and FOAF.

BBC curriculum ontology is considered as a core model for describing the British national curricula using RDF technology. Besides, it organise learning resources and makes them available to the user to discover the content of the national curricula [18].

Higher Education Reference ontology (HERO) is described in [14]. The aim of building HERO is to offer a university domain template of consistent information that can be used as a basis for deriving more precise ontology from the university domain. So, this ontology of reference is intended to be used to define the higher education domain in direction to offer a consistent knowledge of the domain of interest to be shared and reused between diverse users, different communities and different universities. HERO was introduced in OWL 2. Subsequently, it is Reference Ontology, it has a broad and deep exposure of the university domain; in other words, ontology designates numerous features of the university domain such as organizational structure, administration, staff, roles, incomes, etc. The object of this reference ontology is to define any university as important or at least favourable.

Semantic Web for Research Communities (SWRC) ontology describes the main concepts within research communities. As mentioned in [19], the ontology contains six top level concepts, named Publication, Person, Organization, Event, Topic and Project. These concepts were modelled using OWL-DLP ontology language. The main aim of SWRC is to find relations between researchers.

Demartini and his colleagues in [20] have used Bologna reform process for higher education studies to develop an educational ontology called Bowlogna. This ontology describes entities and relations in an academic institution and it aims to support communication and collaboration between universities among European countries. Beside it improves student mobility since it focuses on grading and student's study tracking systems. Additionally, the definitions for all the concepts in Bowlogna ontology are available in the most important languages the used commonly within the European higher education: German, French, Italian and English. This ontology consists of two parts: public part that consists of information that can be shared and private part that stores information that should not be visible to other institutions.

Curriculum-Course-Syllabus-Ontology (CCSO) is an educational ontology that produces the main concepts in higher education (Curriculum, Course, and Syllabus) semantically to support teaching and learning processes within universities [13]. The developers of this ontology have described classes and properties based on the rules of Hellenic Quality Assurance \& Accreditation Agency (HQA) accreditation model in Greece. They also cited the 2013 Computer Science Curricula, a study by the Joint Task Force ACM / IEEE-CS that provide critical guidance on curriculum design and development for computer science undergraduate programs.

CURONTO is another educational ontology that has been designed by researchers from King Saud University (KSU) in Saudi Arabia [21]. The researchers have applied national and international standards to develop their ontological model for curriculum representation. It has been used to promote the review and evaluation of a particular course in higher education. CURONTO supports the decisionmaking process, finding gaps, recognizing repetitions, and identifying standards based on connecting relationships between learning outcomes, learning units, and overall course objectives. This ontology is applied to the Bachelor's Program in Information Technology at KSU as a case study.

OLOUD ontology is a collection of existing ontologies linked to describe course information at Hungarian universities. These data can support the management of the integrated university and building web applications. Also, It helps both students and teachers by providing services such as personal timetables, long time planning, course navigation, university resources usage and other types of services [22]. The main concepts in this ontology are described under the Bologna Process to ensure the compatibility for the European education system.

Table III compares the main terms defined in the existing ontologies. 
TABLE III. COMPARING THE MAIN TERMS OF EXISTING ONTOLOGIES

\begin{tabular}{|c|c|c|c|c|c|c|c|}
\hline \multirow[b]{2}{*}{ 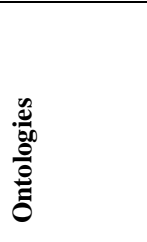 } & \multicolumn{7}{|c|}{ Terms } \\
\hline & 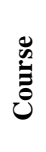 & 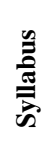 & 冚 & 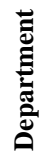 & 兽 & 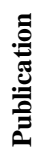 & 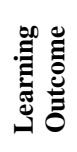 \\
\hline HERO & $\sqrt{ }$ & $\mathrm{X}$ & $\sqrt{ }$ & $\sqrt{ }$ & $\sqrt{ }$ & $\sqrt{ }$ & $X$ \\
\hline AIISO & $\sqrt{ }$ & $\sqrt{ }$ & $\sqrt{ }$ & $\mathrm{X}$ & $\sqrt{ }$ & $X$ & $\mathrm{X}$ \\
\hline Bowlogna & $\sqrt{ }$ & $\sqrt{ }$ & $\mathrm{X}$ & $\mathrm{X}$ & $\sqrt{ }$ & $\mathrm{X}$ & $\sqrt{ }$ \\
\hline $\begin{array}{l}\text { BBC } \\
\text { Curriculum }\end{array}$ & $\sqrt{ }$ & $\sqrt{ }$ & $X$ & $X$ & $\mathrm{X}$ & $\mathrm{X}$ & $\sqrt{ }$ \\
\hline CCSO & $\sqrt{ }$ & $\sqrt{ }$ & $X$ & $\sqrt{ }$ & $\sqrt{ }$ & $X$ & $X$ \\
\hline SWRC & $X$ & $X$ & $X$ & $\sqrt{ }$ & $\sqrt{ }$ & $\sqrt{ }$ & $X$ \\
\hline CURONTO & $\sqrt{ }$ & $\sqrt{ }$ & $\sqrt{ }$ & $\mathrm{X}$ & $\mathrm{X}$ & $X$ & $\sqrt{ }$ \\
\hline OLOUD & $\sqrt{ }$ & $\sqrt{ }$ & $X$ & $\mathrm{X}$ & $\sqrt{ }$ & $X$ & $X$ \\
\hline
\end{tabular}

This revealing process proved the need of creating an ontology from scratch. The existing ontologies can be used as a guideline to model the main concepts in our ontology since they are not covering our requirements. The main reasons of this decision are summarized as follow:

- None of the current ontologies can serve our domain completely to achieve our intended aims

- Universities represent their data using different standards forms. Therefore, the structures of their ontologies are not compatible with our domain

- Although some existing ontologies can be useful, unfortunately, they are not available online

- Most of the reviewed approaches can be similar or either can extend each other. However, most of them describe general points or detail that can be modified or extended in our ontology

2) Specification Phase:

a) The Domain Terms: Before building the main class hierarchy, it is initially important to list all the terms that describe our domain. All the possible words that can describe the domain of education are gathered with the consideration of the CQs, the NCAAA rules, and the policy of KAU. Besides, it is necessary to inspect the terms defined in the existing related ontologies and use them as guidelines to list our terms. Table IV shows the basic terms that we expect to define in the proposed ontology.

b) Classes amd the Class Hierachy: Probably, this is the main step of the development process. To design the class hierarchy, we need to refer to the list of terms in Table IV and choose the most proper concepts that can represent the superclasses and sub-classes. As a result, the total number of the classes that have been described is 15 as shown in Fig. 2.

3) Conceptualization Phase: Since the classes alone are useless, this phase aims to add links between the classes that allow the ontology to answer our inquiries.
TABLE IV. DOMAIN TERMS

\begin{tabular}{|c|c|}
\hline Syllabus & Teaching Staff \\
\hline Course & Faculty \\
\hline Department & Faculty_member \\
\hline Syllabus & Taching_Staff \\
\hline CLO & Research_Work \\
\hline Text_Book & Project \\
\hline Topic & Publication \\
\hline Evaluation & Interested_research_area \\
\hline \multicolumn{2}{|l|}{ Coordinator } \\
\hline & $\begin{array}{l}\text { ember } \\
\text { ic_Staff } \\
\text { stant_Professor } \\
\text { urer } \\
\text { essor } \\
\text { ching_Assistant } \\
\text { ciated_Professor } \\
\text { Work } \\
\text { tion }\end{array}$ \\
\hline
\end{tabular}

Fig. 2. Ontology Class Hierarchy.

a) Relationship between the Classes: This ontology contains two types of properties. Relationships between the classes are presented using 14 object properties. Table V lists the most important object properties. As an instance, "coordinate" and "coordinated_by" are two inversed object properties that describe the relationship between the classes "Academic_Staff" and "Course". On the other hand, there are 26 data properties to describe information about each individual as shown in Fig. 3. For example, "course_title", "course_topics", and "course_description" are used to define instances of the class "Course".

TABLE V. OBJECT PROPERTIES IN THE ONTOLOGY

\begin{tabular}{|l|l|l|}
\hline Object Property & Domain & Range \\
\hline belongs_to & Course & Department \\
\hline coordinate & Academic_Staff & Course \\
\hline coordinated_by & Course & Academic_Staff \\
\hline has_course & Department & Course \\
\hline has_department & Faculty & Department \\
\hline has_member & Department & Faculty_Member \\
\hline member_of & Faculty_Member & Department \\
\hline part_of & Department & Faculty \\
\hline prerequisite & Course & Course \\
\hline prerequisite_by & Course & Course \\
\hline
\end{tabular}




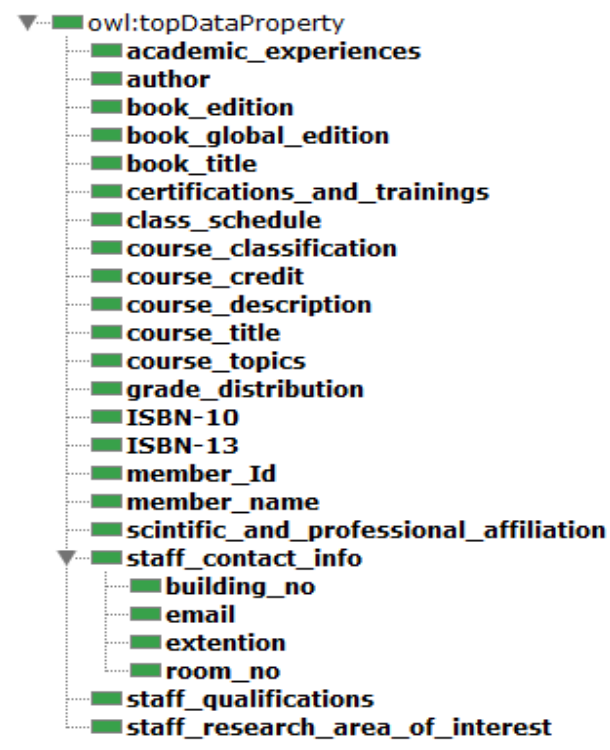

Fig. 3. Data Property Hierarchy.

4) Formalization and Implementation phase:

a) Create Instances: After creating all the needed classes and properties and completing the ontology model, instances (individuals) can be described. This step involves selecting a unique name for each individual, specifying the class to which it belongs, and defining its attributes values (data properties). Fig. 4 summarizes part of the ontology metric, including the number of the created individuals.

\begin{tabular}{|c|c|}
\hline Ontology metrics: & \\
\hline \multicolumn{2}{|l|}{ Metrics } \\
\hline Axiom & 7564 \\
\hline Logical axiom count & 7068 \\
\hline Declaration axioms count & 496 \\
\hline Class count & 15 \\
\hline Object property count & 14 \\
\hline Data property count & 26 \\
\hline Individual count & 442 \\
\hline
\end{tabular}

Fig. 4. Individuals in the Ontology.

\section{Evaluation}

In this critical step, the CQs are used again to find the results of our research questions and to evaluate the ontology. SPARQL queries are extracted from the questions then executed using the feature tab "SPARQL query" in Protégé. Table VI shows the most important examples of SPARQL queries that used in the evaluation process.

Using the CQs technique has confirmed the sufficiency of the knowledge represented in the ontology and shows how it could answer the queries that extracted from the CQs.
TABLE VI. EXAMPLES OF SPARQL QUERIES EXTRACTED FROM CQS

\begin{tabular}{|c|c|}
\hline CQs Example & SPARQL Query \\
\hline $\begin{array}{l}\text { - Who can teach } \\
\text { which course? }\end{array}$ & $\begin{array}{l}\text { SELECT ?Department ?Course ?Teacher ?Topic } \\
\text { WHERE \{ ?Course dss:belongs_to ?Department. } \\
\text { ?Teacher dss:member_of ?Department. } \\
\text { ?Course dss:course_topics ?Topic. } \\
\\
\text { ?Teacherdss:staff_research_area_of_interest } \\
\text { ?Topic\} } \\
\text { ORDER BY ?Department }\end{array}$ \\
\hline $\begin{array}{l}\text { Which academic } \\
\text { teacher the best to } \\
\text { teach a particular } \\
\text { course (e.g. } \\
\text { "CourseA")? }\end{array}$ & $\begin{array}{l}\text { SELECT ?Teacher } \\
\text { WHERE \{?Course dss:belongs_to ?Department. } \\
\text { ?Teacher dss:member_of ?Department. } \\
\text { ?Course dss:course_topics ?Topic. } \\
\text { ?Teacher dss:staff_research_area_of_interest } \\
\text { ?Topic. } \\
\text { ?Course dss:course_title ?aa } \\
\text { FILTER regex(?aa, "^ CourseA ").\} }\end{array}$ \\
\hline $\begin{array}{l}\text { Which course is } \\
\text { best to be taught } \\
\text { by a particular } \\
\text { academic teacher } \\
\text { (e.g."Teacher1"?) }\end{array}$ & $\begin{array}{l}\text { SELECT ?Course } \\
\text { WHERE \{?Course dss:belongs_to ?Department. } \\
\text { ?Teacher dss:member_of ?Department. } \\
\text { ?Course dss:course_topics ?Topic. } \\
\text { ?Teacher dss:staff_research_area_of_interest } \\
\text { ?Topic. } \\
\text { ?Teacher dss:member_name ?aa } \\
\text { FILTER regex(?aa, "^Teacher1").\} }\end{array}$ \\
\hline
\end{tabular}

\section{DISCUSSION}

To judge the accuracy of the results from the evaluation process, there is a need to build more SPARQL queries that return digit results to give a clear picture of the main results and to make a comprehensive comparison.

Hint, the evaluation was applied to the Ph.D. holders only since they are usually engaged in research activities and publish journals and conferences. Besides, the courses are taught by them when most of the non-Ph.D. holders are considered as teaching assistants. So, there are no records of their interesting research area. At the same time, all the academic teachers' profiles in the faculty, from all the degrees, have translated into RDF format for future processes.

To find the number of teachers who are allocated to teach courses, we used the query mentioned in Fig. 5. This query counts the teachers depending on their interesting research area that match topics of courses or if they are coordinators of any courses within the same department.

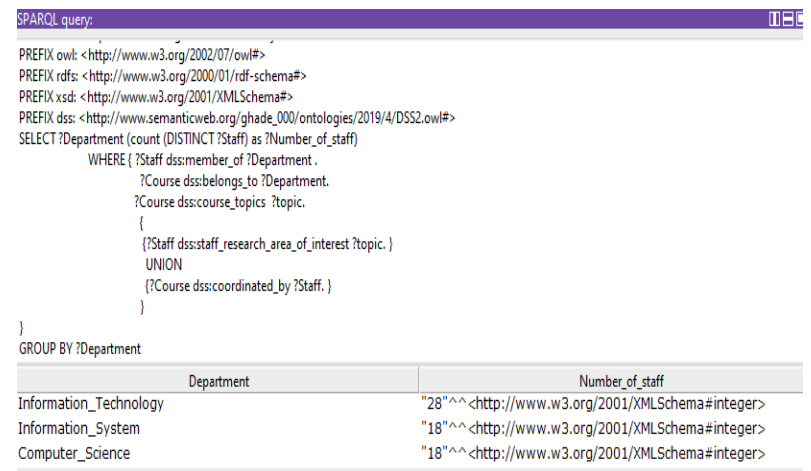

Fig. 5. Counting the Allocated Academic Teachers in Protégé. 
By comparing these numbers with the total number of teachers (see Fig. 6); we find that only $40 \%$ of the academic teachers in the Information System department were allocated to teach courses when nearly $36 \%$ of the Computer Science department teachers are allocated. On the other hand, 53\% of the academic staff members in the Information Technology department are allocated to teach courses from the same department.

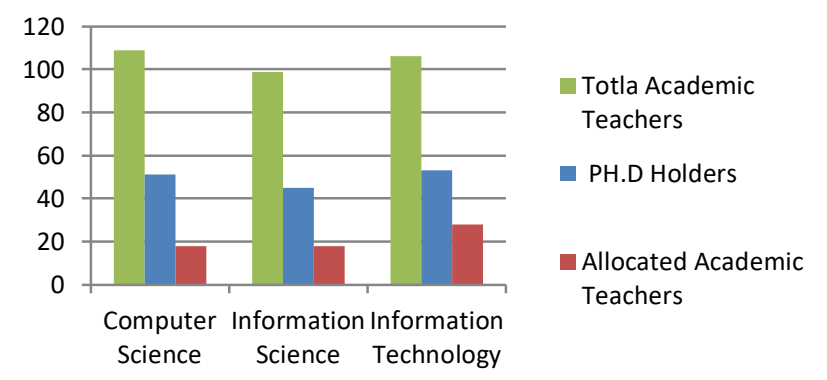

Fig. 6. Comparing the Number of Allocated Academic Teachers with the Total Number.

Fig. 7 below describes the SPARQL query that counts the numbers of the courses that are assigned to academic teachers in each department.

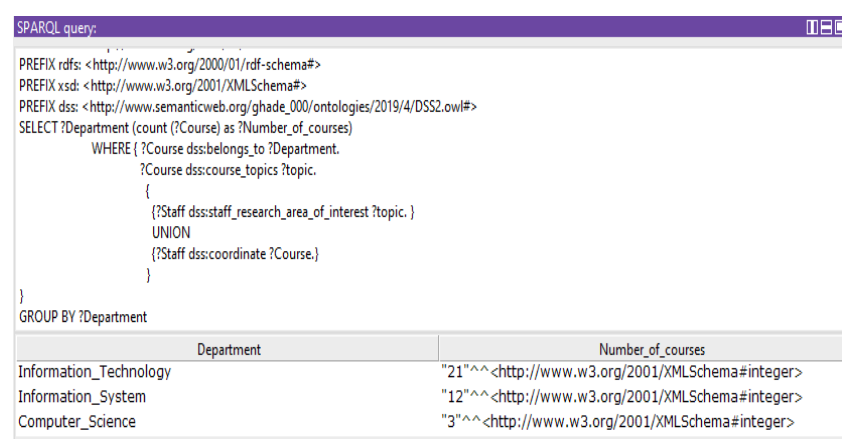

Fig. 7. Counting the Courses Assigned to Teachers in Protégé.

According to Fig. 8, more than half of the courses in the Information System department not assigned to any teacher since only $30 \%$ of them are assigned. Also, it is mentioned that only $7 \%$ of the courses in the Computer Science department are assigned to teachers. On the other hand, $62 \%$ of the courses are assigned to teachers in the Information Technology department.

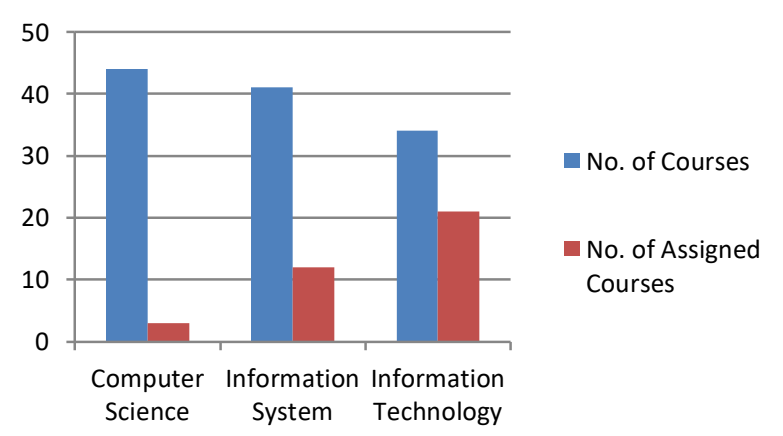

Fig. 8. Comparing the Assigned Courses with Total Number of Courses.
Although the percentages that are shown in the evaluation process are small, still using the semantic technology for allocating the best academic reference for teaching courses gives accurate and faster results than the manual process. So, the results show that more than half of the academic teachers would not be assigned to any course. At the same time, a large number of courses were not matched with any academic teacher. This keeps the need to use the manual process for these remain data.

By referring to the data, it is found that each teacher belongs to one of the cases below:

- Allocated teachers: the teachers who are listed in the results. e.g. "Teacher1" has been chosen to teach "CourseA" when we check the results we found that there is a match between the topics of "CourseA" and the research area of interest for "Teacher1".

- Not Allocated teachers: the teachers who are not listed in the results:

○ Caused by incomplete data: e.g. "Teacher2" has not been assigned to "CourseB" although he is teaching this course according to the manual matching. This is because the details for "Teacher2" are not completed especially the areas of interest record.

○ Caused by incompatible data: e.g. "Teacher3" has been missed in the results we have while he can teach "CourseC" according to his specialty, and his profile is completed. When we refer to his records, we found that his areas of interest are written as abbreviations when the topics are mentioned in full description.

That end up with the main reason why this shortage appears is that while the details of all the courses are completed, some academic teachers not describing their research areas of interest correctly or not mentioning them in their profiles.

As an initial suggestion to overcome this shortage, proper external repositories can be used to complete the missing data and rich the matching criteria by leveraging the semantic with linked data technique in future work.

\section{CONCLUSION}

Text Modernization spreads in the education domain in the last few years. This leads several researchers to find solutions for the challenges caused by this modernization. This work supports the decision-making process within universities by proposing an ontology that demonstrates courses and academic profiles semantically. Using semantic technology can make dealing with the continuously increasing amount of data, universities usually have, easier. The study aims to solve the challenge of allocate the most proper academic teacher to teach a new course. To apply this study, King Abdulaziz University was the case study focusing on the Faculty of Computing and Information Technology including its three departments that follow the NCAAA rules for documenting their data. 
Developing the ontology consists of some processes. First, the domain was described to determine the scope of the ontology. Then, several existing ontologies were reviewed to test the ability to reuse them but, none of them was appropriate with our criteria so, the ontology was developed from scratch. According to the domain description, the textual data for 119 courses and 314 academic teachers' profiles are transferred into the RDF format. After that, the relations between these concepts were defined via object and data properties. To complete the vision of the wok, some individuals have been created.

The evaluation process included using the CQs technique. The test showed that although a significant number of courses and teachers have not been assigned, still the system gives accurate results. In the future, external repositories can be used to solve this shortage. The system can be extended to support more decisions within universities or to solve more educational challenges. Besides, it can be reused by other universities specially the Saudi universities that apply NCAAA rules.

\section{ACKNOWLEDGMENTS}

The authors are very grateful for the Faculty of Computer and Information Technology at King Abdulaziz University for providing the data needed in this work. Also, many thanks to Dr.Naif Aljohani for his generous support.

REFERENCES

[1] M. Tapia-Leon, A. C. Rivera, J. Chicaiza and S. Luján-Mora, Application of ontologies in higher education: A systematic mapping study, 2018 IEEE Global Engineering Education Conference (EDUCON), IEEE, 2018, pp. 1344-1353.

[2] B. Daggett, Addressing Current and Future Challenges in Education, Model Schools Conference, 2014.

[3] B. Daniel, Big Data and analytics in higher education: Opportunities and challenges, 2015.

[4] F. Sarker, H. Davis and T. Tiropanis, A review of higher education challenges and data infrastructure responses, (2010).

[5] G. Ashour, A. Al-Dubai, I. Romdhani and N. Aljohani, An Ontological Model for Courses and Academic Profiles Representation: A case study of King Abdulaziz University, 2020 International Conference Engineering Technologies and Computer Science (EnT), IEEE, 2020, pp. 123-126.

[6] P. Ristoski and H. Paulheim, Semantic Web in data mining and knowledge discovery: A comprehensive survey, Web semantics: science, services and agents on the World Wide Web, 36 (2016), pp. 122.

[7] S. Kabir, S. Ripon, M. Rahman and T. Rahman, Knowledge-based data mining using semantic web, IERI Procedia, 7 (2014), pp. 113-119.

[8] E. Blomqvist, The use of Semantic Web technologies for decision support-a survey, 2014.

[9] C. Sarmiento, O. Duarte, M. Barrera and R. Soto, Semi-automated academic tutor for the selection of learning paths in a curriculum: An ontology-based approach, 2016 IEEE 8th International Conference on Engineering Education (ICEED), 2016, pp. 223-228.

[10] M. E. Ibrahim, Y. Yang, D. L. Ndzi, G. Yang and M. Al-Maliki, Ontology-based personalized course recommendation framework, IEEE Access, 7 (2018), pp. 5180-5199.

[11] N. Piedra, E. Tovar, R. Colomo-Palacios, J. López and J. Chicaiza, Consuming and producing linked open data: The case of OpenCourseWare, 2014.

[12] H. Chung and J. Kim, An Ontological Approach for Semantic Modeling of Curriculum and Syllabus in Higher Education, 2016.

[13] E. Katis, H. Kondylakis, G. Agathangelos and K. Vassilakis, Developing an Ontology for Curriculum and Syllabus, European Semantic Web Conference, Springer, 2018, pp. 55-59.

[14] L. Zemmouchi-Ghomari and A. R. Ghomari, Process of building reference ontology for higher education, 2013.

[15] N. F. Noy and D. L. Mcguinness, Ontology development 101: A guide to creating your first ontology, Stanford knowledge systems laboratory technical report KSL-01-05 and ..., 2001.

[16] A. Abou-Zeid and M. A. Taha, Accreditation process for engineering programs in Saudi Arabia: Challenges and lessons learned, 2014 IEEE Global Engineering Education Conference (EDUCON), 2014, pp. 11181125 .

[17] J. Cardoso, A. Lisete and N. Escórcio, Editing Tools for Ontology Construction, Idea Group (2007).

[18] BBC, "BBC Curriculum Ontology,” 2013. [Online]. Available: https://www.bbc.co.uk/ontologies/curriculum.

[19] Y. Sure, S. Bloehdorn, P. Haase, J. Hartmann and D. Oberle, The SWRC ontology-semantic web for research communities, Portuguese Conference on Artificial Intelligence, Springer, 2005, pp. 218-231.

[20] G. Demartini, I. Enchev, J. Gapany and P. Cudré-Mauroux, The Bowlogna ontology: Fostering open curricula and agile knowledge bases for Europe's higher education landscape, Semantic Web, 4 (2013), pp. 53-63.

[21] A. Alfaries, M. Al-Yahya, H. Chorfi and R. George, Curonto: A Semantic Model of the Curriculum for Program Assessment and Improvement, 2014.

[22] B. Szász, R. Fleiner and A. Micsik, A Case Study on Linked Data for University Courses, Springer International Publishing, Cham, 2017, pp. 265-276. 